\title{
Implantação de programa de controle de qualidade numa indústria pesqueira do Rio Grande do Sul
}

\section{Implementation of the quality control program in a fishing industry in Rio Grande do Sul}

\author{
Maria Inês Rodrigues Machado ${ }^{1 *}$, Adriana Rodrigues Machado ${ }^{2}$
}

\begin{abstract}
RESUMO
O Programa de Análise de Perigos e Pontos Críticos de Controle (APPCC) engloba todo sistema de produção, estruturando a empresa dentro de procedimentos que tornem o funcionamento da planta controlado. Abrange matérias-primas, insumos, procedimentos, análises físicas, químicas e microbiológicas que afetam cada operação subseqüente e o produto e é recomendado por organismos internacionais, sendo no Brasil responsabilidade dos Ministérios da Saúde e Ministério da Agricultura e Abastecimento. O objetivo deste trabalho foi acompanhar a implantação do programa APPCC (Analise de Perigo e Pontos críticos de controle) em uma indústria pesqueira da cidade do Rio Grande - RS, que processa pescado inteiro, eviscerado, filé, postas congelado ou fresco e também salgado.As metodologias aplicadas foram: Implantação do Programa de APPCC, Avaliação físico-química e microbiológica da matéria-prima. Estes resultados foram obtidos ao longo de sete meses, para depois liberar as exportações. Portanto, os indicadores de qualidade, tanto físicos, químicos e microbiológicos são constantemente avaliados apresentando até o momento resultados favoráveis e dentro das recomendações da legislação brasileira, indicando que as amostras avaliadas encontravam-se aptas ao consumo.
\end{abstract}

Palavras-chave: Análise; Perigos; Controle; Pescado.

\begin{abstract}
The Hazard Analysis and Critical Control Points Program (HACCP) encompasses the entire production system, structuring the company within procedures that make the plant's operation controlled. It covers raw materials, inputs, procedures, physical, chemical, and microbiological analyses that affect each subsequent operation and the product and is recommended by international organizations, being in Brazil the responsibility of the Ministries of Health and the Ministry of Agriculture Supply. This work's objective was to monitor the implementation of the HACCP program (Hazard Analysis and Critical Control Points) in the fishing industry in the city of Rio Grande - RS, which processes whole, gutted, fillet, frozen, or fresh fish and salted fish. The methodologies applied were Implementation of the HACCP Program, Physicalchemical and microbiological evaluation of the raw material. These results were obtained over seven months, after which exports were released. Therefore, quality indicators, both physical, chemical, and microbiological, are constantly evaluated, showing favorable results so far and within the recommendations of Brazilian legislation, indicating that the samples evaluated were suitable for consumption.
\end{abstract}

\footnotetext{
${ }^{1}$ Universidade Regional do Cariri, Brasil1.

*E-mail:ines.machado@ufca.edu.br

${ }^{2}$ Universidade Federal de Pelotas, Brasil
} 


\section{INTRODUÇÃO}

O pescado (peixes, moluscos e crustáceos) é considerado desde a antiguidade uma importante fonte de alimentos. A sua pesca constitui uma atividade econômica promotora de benefícios sociais para as populações humanas em todo o mundo (Afonso, 2016). Além de ser rico em proteínas, o pescado possui aminoácidos essenciais ao crescimento e manutenção do organismo humano (Lira \& Pereira, 2001).

O pescado é considerado um alimento de alta digestibilidade, no entanto, pela sua própria composição, é um dos mais perecíveis, necessitando de cuidados adequados de manipulação, desde a captura até o consumo ou industrialização(Souza et al., 2015).

Do total de 970 mil pescadores registrados no Brasil pelo Ministério da Pesca e Aquicultura, 957 mil são pescadores artesanais. Estes estão organizados atualmente em cerca de 760 associações, 137 sindicatos e 47 cooperativas (BRASIL, 2011).

A necessidade de garantir a qualidade de seus produtos e a concorrência está levando o setor pesqueiro a investir em programas de controle de qualidade, como as Boas Práticas de Fabricação e o PPHO (Procedimento Padrão de Higiene Operacional). A partir da implantação destes programas, a empresa encontra-se apta para desenvolver o APPCC (Análise de Perigos e Pontos Críticos de Controle), um dos mais aplicados à indústria pesqueira, que é baseado na identificação dos perigos potenciais à segurança do alimento e estabelece medidas controladoras das condições geradoras destes perigos (FAO, 1985; Stevenson \& Bernard, 1995; Ropkins \& Beck, 2000).

A garantia da qualidade passa a ser de primordial importância para que se estabeleça uma relação de confiança entre consumidor e produtor. Essa garantia está baseada em atividades (controle de qualidade de um produto ou serviço) que resguardem o consumidor de falhas (Colleto, 2012). O processo de implantação de sistemas de gestão agrega valor à cultura organizacional, desenvolvendo competências relacionadas com o planejamento, atuação proativa, capacidade de trabalho em equipe e melhoria da confiabilidade dos sistemas produtivos (Silva, et al., 2012).

A possibilidade de rastrear a origem de um produto final através de um sistema de documentação e registros deve ser uma condição prévia para todo sistema de administração da qualidade (Mortajemi, 2000, SEBRAE, 2000). 
Sendo assim, os objetivos deste trabalho foram: implantar o programa de controle de qualidade no processo de obtenção de pescado inteiro congelado, pescado eviscerado congelado, pescado em postas congelado, filé de pescado congelado em indústria de pescado da região Sul do Estado do Rio Grande do Sul; identificar os perigos químicos, físicos e microbiológicos no processamento; e caracterizar as condições da matéria-prima e do produto, através da realização de determinações físico-químicas, sensoriais e microbiológicas.

\section{MATERIAL E MÉTODOS}

A presente pesquisa caracterizou-se como um estudo laboratorial (quantitativo) e qualitativo, com isso os métodos qualitativos são aqueles nos quais é importante a interpretação por parte do pesquisador com suas opiniões sobre o fenômeno em estudo, assim como a tornasse importante a prática reflexiva de ênfase social que se investiga e do processo de investigação (Pereira, et al. 2018).

\section{Implantação do Programa de APPCC (Tabela 1)}

O trabalho foi realizado em uma Indústria Pesqueira da cidade do Rio Grande, no Rio Grande do Sul, que conta com 100 funcionários. Iniciou através da formação de uma equipe de trabalho multidisciplinar, seguido recomendações de Ropkins \& Beck, (2000); SEBRAE, (2000). Como principais requisitos necessários para elaboração do plano foram estabelecidos:

1) Organogramas da empresa.

2) Descrições do processo de fabricação;

3) Memorial descritivo e fluxograma de cada processo, Mortajemi (2000);

4) Identificações dos PCCs (Pontos Críticos de Controle) e PC (Pontos de Controle) Ogawa \& Maia, (1999);

5) Estabelecimentos de medidas preventivas, limites críticos e procedimentos de monitorização;

6) Procedimentos de Registro;

7) Manutenção das BPFs; Andras, Dutra, Szpakowisk, (2000).

8) Avaliação sensorial do pescado no setor de recepção; CODEX, (1997). 
Tabela 1 - Quadro Resumo Filé de Pescado Congelado

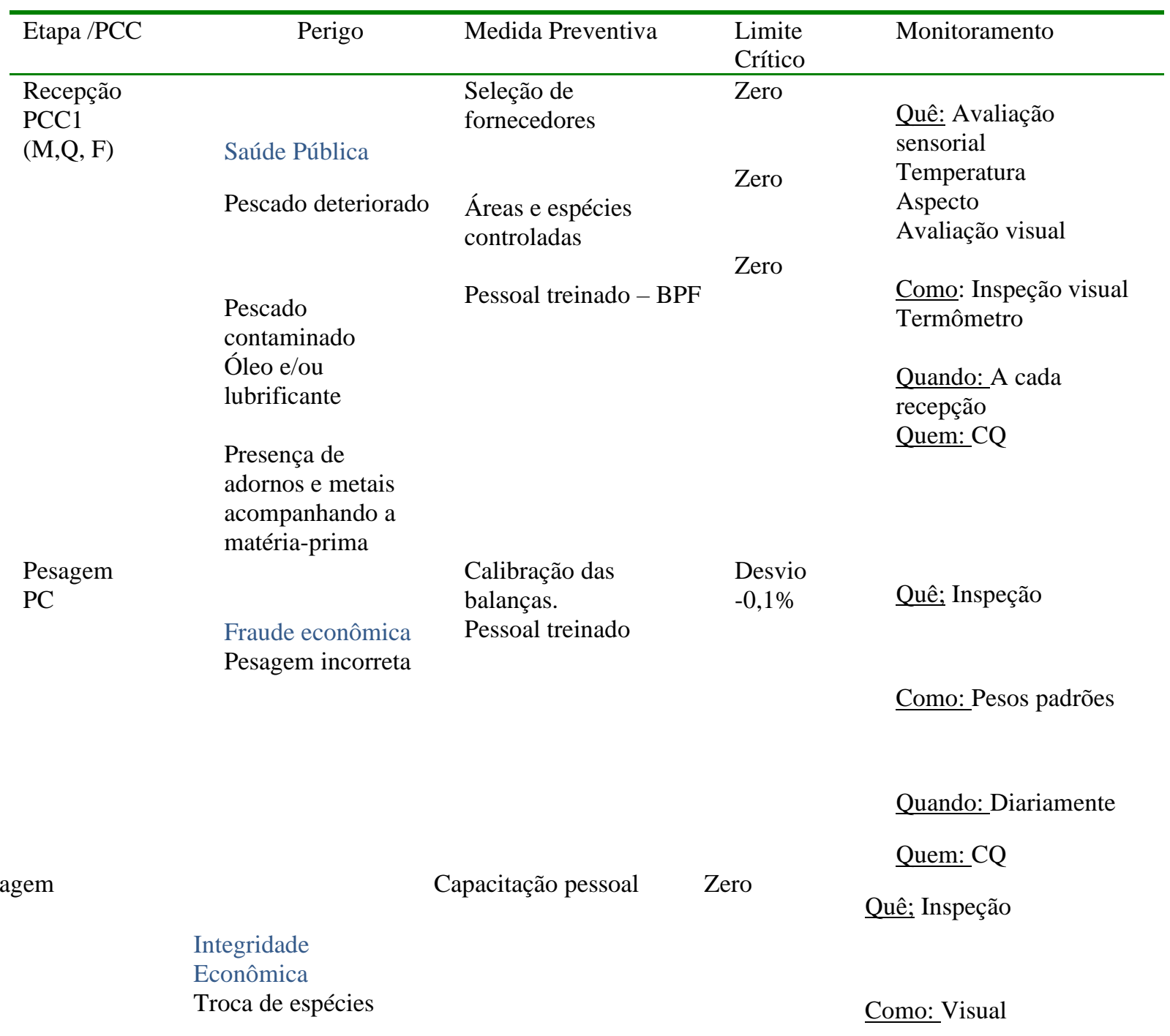

Quando:Diariamente

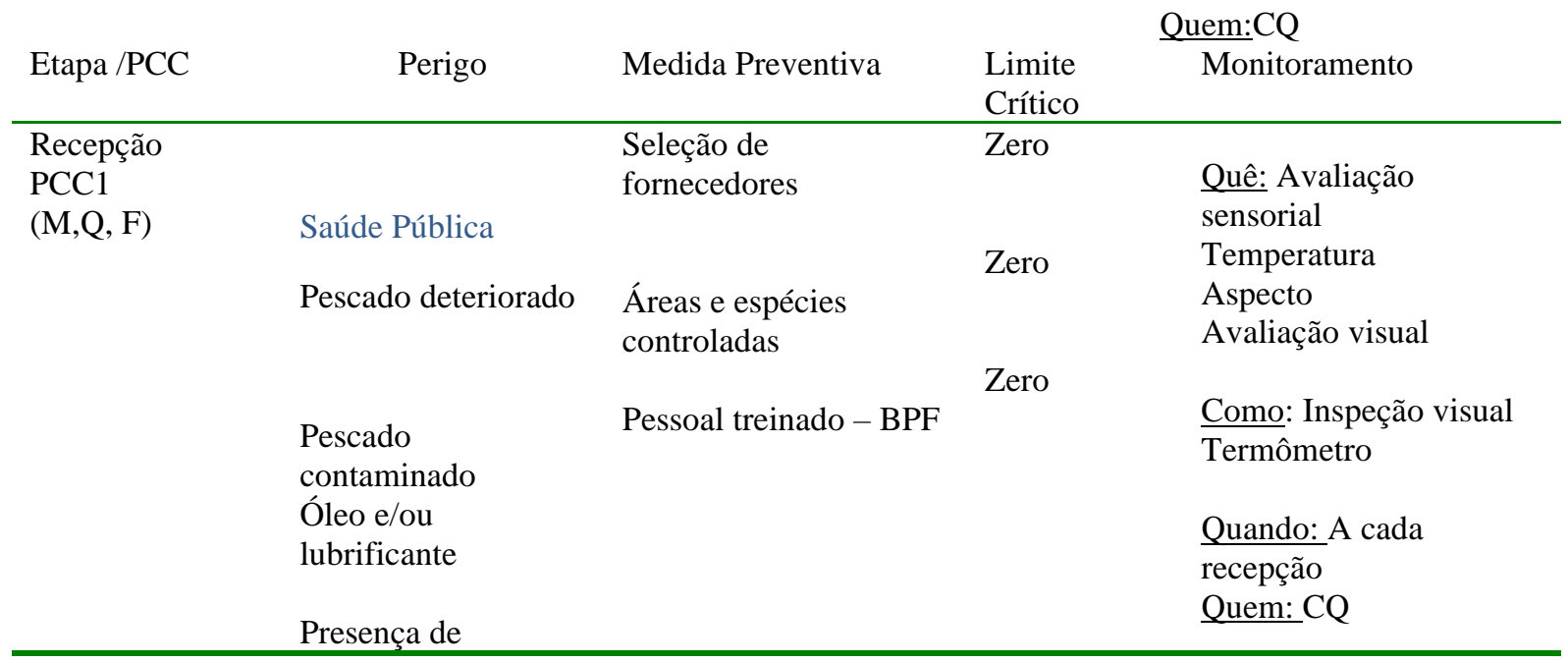


adornos e metais acompanhando a matéria-prima

Pesagem

PC

Fraude econômica Pesagem incorreta

Embalagem PC
Calibração das

balanças.

Pessoal treinado

Desvio

$-0,1 \%$

Quê; Inspeção

Como: Pesos padrões

Quando: Diariamente

Quem: CQ

Capacitação pessoal

Zero

Quê; Inspeção

Como: Visual

Integridade

Econômica

Troca de espécies

Quando: Diariamente

Quem: CQ

PCC1: Ponto Critico de controle; (M,Q, F):Microbiológico, Físico e químico; PC : ponto de controle Fonte: Autoria própria.

\section{Avaliação físico-química e microbiológica da matéria-prima}

\section{Bases voláteis totais, trimetilamina (BRASIL, 1993)}

Realizadas por amostragem, obedecendo a tabela do CODEX, (1997); de acordo com a classificação obtida na recepção do pescado

\section{Avaliação microbiológica da matéria-prima e do produto final}

As determinações realizadas foram as seguintes: Clostridium Sulfito

Redutores, Contagem de Coliformes Totais e Fecais, Contagem de Fungos e Leveduras, Contagem de Microrganismos Aeróbios Restritos Facultativos Viáveis, Contagem de Staphylococcus aureus e Salmonella. As espécies escolhidas para realizar as determinações microbiológicas foram: castanha (Umbrinacanosai), pescada (Macrodonancylodon), corvina (Micropogoniasfurnieri), linguado (Paralichtys spp.), abrótea (Urophycis brasiliensis), caçonete (Musteusschmitti), disponíveis ou classificadas como irregular para os mais diversos destinos (BRASIL, 1993; ABIA, 2000). 


\section{RESULTADOS E DISCUSSÃO}

\section{Elaboração do mapa organizacional da empresa}

Seguindo as recomendações de Mortimore, (2000); o setor de controle de qualidade foi especificado no organograma (Figura 1) para que mantivesse contato direto com a direção da empresa e com o setor de produção. Esta ligação favorece o desenvolvimento do programa, informando diretamente à direção, as modificações, investimentos e resultados obtidos.

Figura 1-Organograma operacional da indústria de processamento de pescado de Rio Grande - RS.

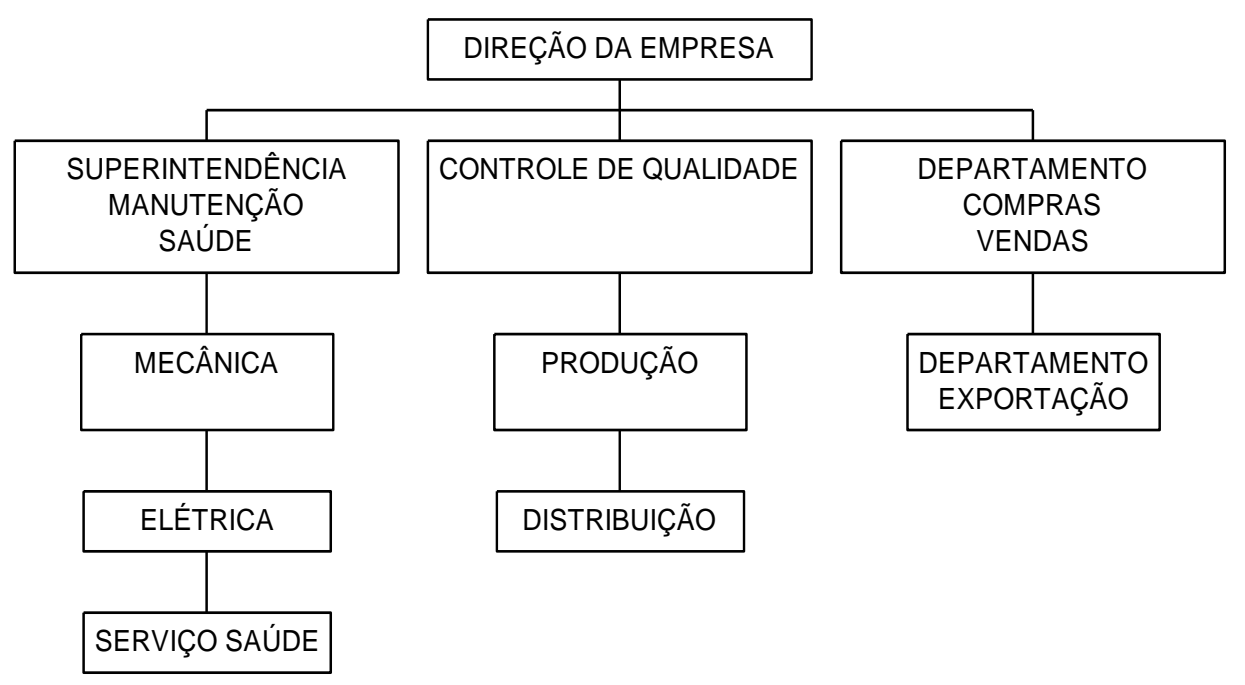

Elaboração do memorial descritivo e dos fluxogramas dos processos, identificação dos PCC e PC. 
Figura 2-Fluxograma dos diferentes processamentos na indústria pesqueira PCC- Ponto crítico de controle/PC Ponto de controle

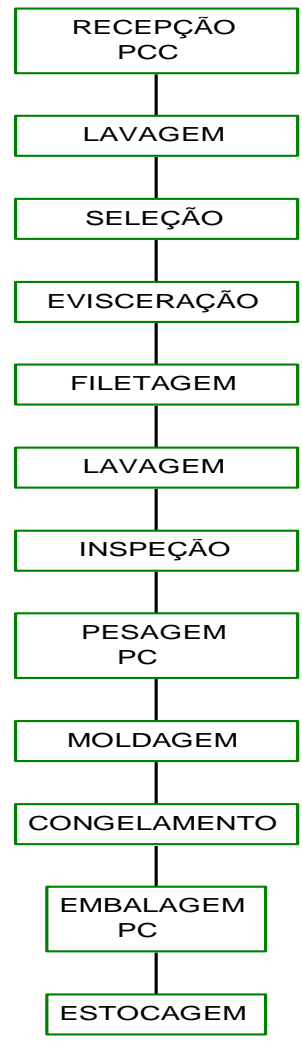

Filé de Peixe Congelado

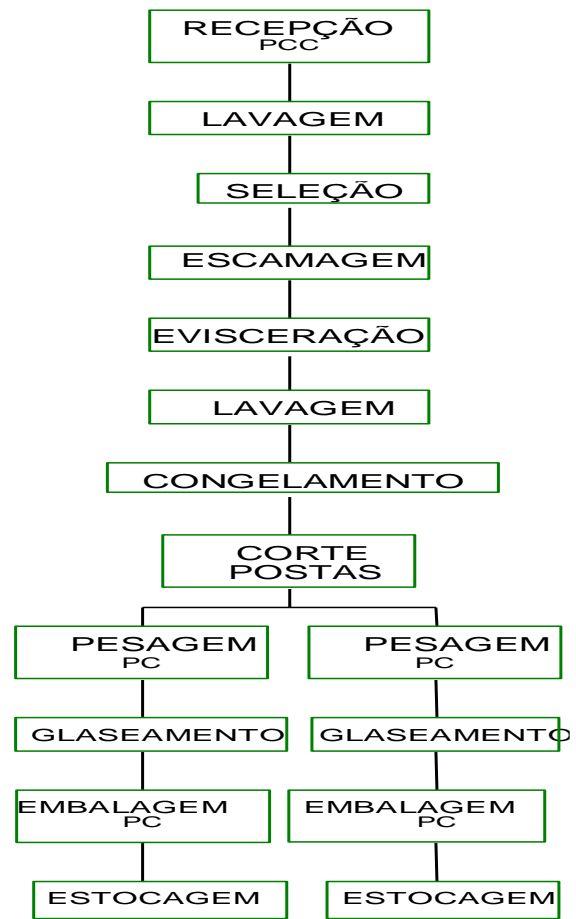

Peixe em postas Congelado

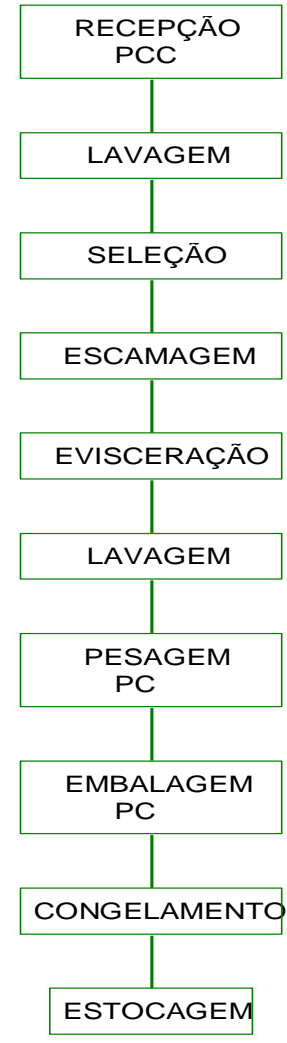

Peixe Eviscerado Congelado

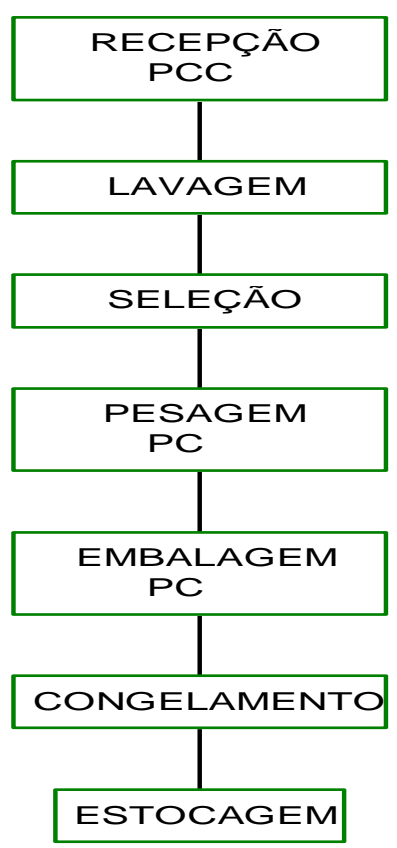

Peixe Congelado Inteiro

Fonte: Autoria própria. 
Estabelecimento de medidas preventivas, limites críticos e procedimentos de monitorização e preenchimento de planilhas.

Com base nos seguintes critérios: problemas de saúde pública e integridade econômica foram descritos em um quadro resumo os PCC e PC que podem ocorrer no processamento de pescado, seguido das medidas preventivas, limite crítico e procedimentos de monitorização, que foram registrados em planilhas específicas.

Com relação ao limite crítico adotado pela empresa, especificamente o desvio de $-0,1 \%$ na pesagem vem a favorecer diretamente o consumidor, esta medida elimina possíveis irregularidades que possam ocorrer na pesagem; mesmo levando em consideração o fato de a empresa possuir colaboradores treinados e fixos para este setor, e contrato mensal com uma empresa que realiza calibração de balanças.

A pesagem do pescado foi considerada como ponto de controle (PC), porque neste ponto podem ocorrer problemas de fraude econômica. Como medidas preventivas são utilizados funcionários treinados e específicos para função, calibração mensal das balanças por empresa terceirizada e aferição a cada utilização através de pesos padronizados.

Outro ponto de controle, considerado foi à embalagem do produto, que é uma etapa de suma importância, pois as ocorrências de erros neste momento podem ser irreversíveis, porque, ao sair do túnel de congelamento não existem etapas posteriores para corrigir esta falha.

\section{Resultado das determinações físico-químicas na matéria-prima e no}

\section{produto final.}

\section{Bases Voláteis Totais(N-BVT) e Trimetilamina (TMA)}

Através dos resultados obtidos, foi verificado que as amostras encontravam-se dentro dos padrões da literatura, pode-se confirmar que as espécies estudadas apresentaram semelhantes aos métodos de Brasil 1999, respectivamente para Pescada e Tilápia :18,34 e 11,35 (mg N/ 100 g), estudado por Cicero et al., (2014). Com isso, as bases voláteis totais aumentam à medida que o pescado se deteriora (Santos, 2013).

Os valores estudados, Tabela 2, apresentaram valores de N-BVT abaixo do limite estipulado pelo Ministério da Agricultura, Pecuária e Abastecimento (BRASIL, 1997), de $30 \mathrm{mg} \mathrm{N} / 100 \mathrm{~g}$ de pescado (Cicero et al., 2014). 
Tabela 2-Bases voláteis totais $(\mathrm{mg} / 100 \mathrm{~g})$ e Trimetilamina $(\mathrm{mg} / 100 \mathrm{~g})$ para pescado fresco.

\begin{tabular}{llll}
\hline Espécie & Nome Científico & BVT & TMA \\
\hline Linguado & (Paralichtys spp. & 24,57 & 0,90 \\
Pescada & (Macrodonancylodon) & 23,20 & 2,23 \\
Castanha & (Umbrinacanosai) & 18,90 & 5,10 \\
Papa-terra & (Menticirrhusmartinicensis) 12,20 & 1,62 \\
Corvina & (Micropogoniasfurnieri) & 18,45 & 4,53 \\
Caçonete & (Musteusschmitti) & 21,90 & 1,10 \\
Viola & (Rhinobatosborkelli) & 19,23 & 3,40 \\
Miragaia & (Pogoniascromis) & 15,50 & 3,21 \\
\hline
\end{tabular}

TMA- 6 mg/100g; BVT-30 a 35 mg/100g., BRASIL, (1993a)

A trimetilamina é uma substância peculiar de peixes e crustáceos, distribuídas nos músculos e vísceras, mas no pescado fresco apresentam-se em quantidade insignificantes. Porém, após a morte a quantidade de TMA aumenta em decorrência da degradação do óxido de trimetilamina por ação das redutasas bacterianas (Santos, 2013).

Para complementar os resultados de BVT e TMA, foram realizadas determinações microbiológicas que não apresentaram alterações.

\section{Determinações microbiológicas do pescado fresco e do produto final}

O pescado é um alimento altamente perecível, decorrente dos fatores microbiológicos, da rápida instalação da fase de rigidez pós-morte, da liberação do muco, da alta quantidade de água nos tecidos, constituição do tecido conjuntivo e do tecido rico em proteínas, fofolipídeos e ácidos graxos. Logo após sua morte, o pescado sofre uma série de alterações pela ação de enzimas musculares que hidrolisam proteínas e lipídeos e na sequência inicia-se a degradação microbiana que provoca alterações químicas e físicas gradativas e irreversíveis (Vieira, 2011). 
Os microrganismos são encontrados nas superfícies externas (pele e brânquias) e nos intestinos dos peixes vivos e recém capturados, que podem variar bastante em relação a sua quantidade e natureza (Amaral \& Freitas, 2013).

Os resultados das determinações microbiológicas do pescado fresco e do produto final encontram-se na Tabela 3 a seguir: 
Tabela 3- Determinações microbiológicas do Pescado Fresco e do Produto Final.

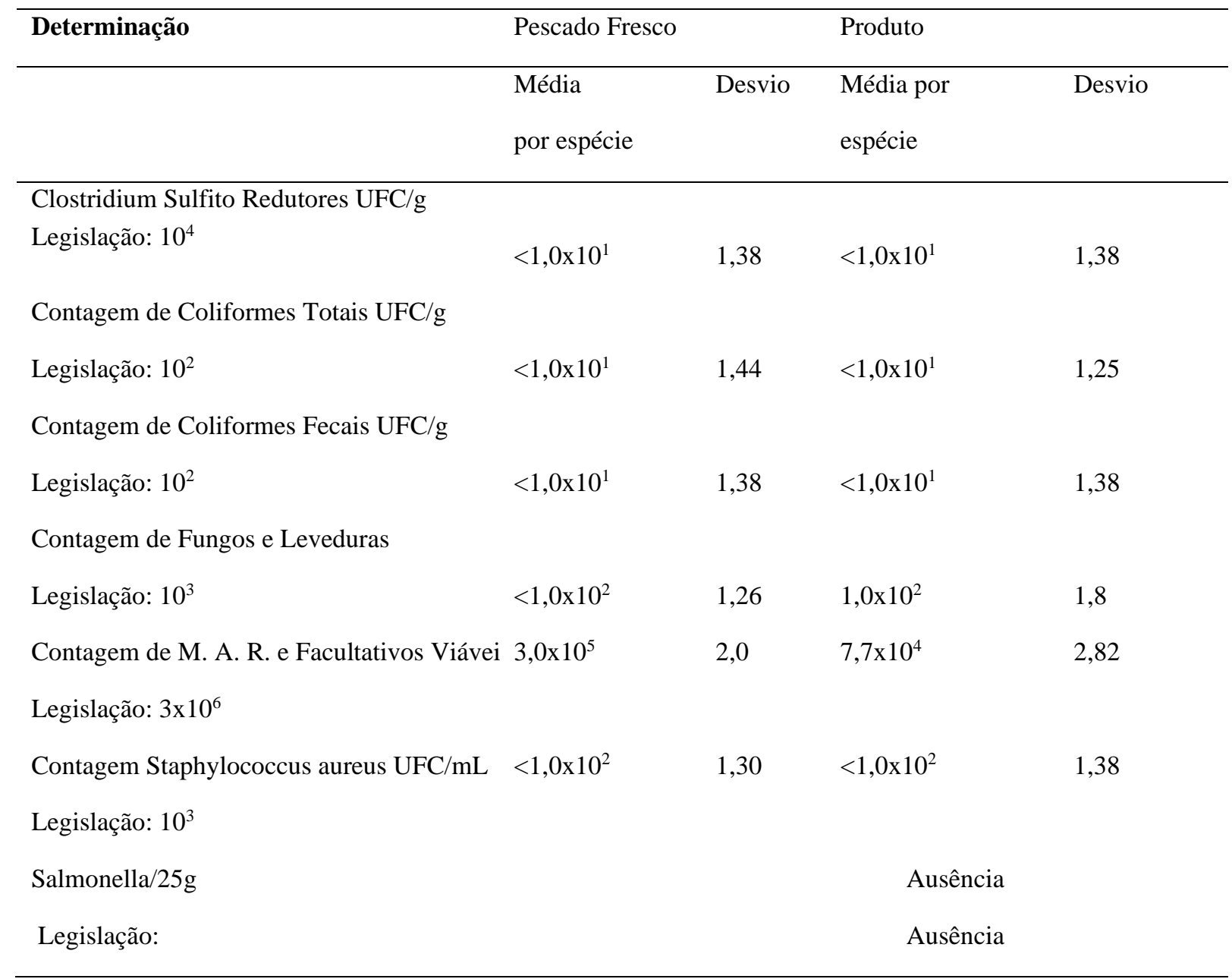

Fonte: Autoria própria.

\section{CONCLUSÃO}

As boas práticas de fabricação e o programa de controle de qualidade APPCC foram implantados e permanecem em constante monitoramento. Os indicadores da qualidade físico-química e microbiológica apresentaram valores dentro dos padrões de legislação, indicando que as amostras avaliadas se encontravam aptas ao consumo. Através da árvore decisória e avaliação dos perigos foram determinados os Pontos de Controle (pesagem e embalagem) e um Ponto Crítico de Controle (Recepção) no processamento do pescado na indústria de Rio Grande. 


\section{REFERÊNCIAS}

ABIA. ASSOCIAÇÃO BRASILEIRA DAS INDÚSTRIAS DE ALIMENTAÇÃO: COMPÊNDIO DA LEGISLAÇÃO DE ALIMENTOS, REVISÃO 8.2000.

ANDRAS, G., DUTRA, I.Z., SZPAKOWSKI, V. Boas Práticas de Fabricação, Porto Alegre- RS, p. 13-27, 2000.

AFONSO, A. N. L. Avaliação da qualidade microbiológica de peixe corvina (argyrosomusthorpei) fresco e congelado descarregado no porto de pesca da Beira. 2016, p.58. Trabalho de licenciatura em engenharia alimentar. Universidade Católica de Moçambique faculdade de engenharia., Chimoio, Moçambique, 2016.

AMARAL, G. V. D., \& FREITAS, D. D. G. C. Quality index method to determine the freshness of fish. Ciência Rural, 43(11), p.2093-2100, 2013.

BRASIL, Ministério da Agricultura, Secretaria Nacional de Abastecimento. Normas de Identidade, Qualidade, Embalagem e Apresentação, Brasília, v.8, n-20,1993a.

BRASIL. Ministério da Agricultura, Pecuária e Abastecimento. Secretaria de Defesa Agropecuária. Instrução Normativa $\mathrm{n}^{\circ}$ 20, de 21 de Julho de 1999. Métodos analíticos físico químicos para controle de produtos cárneos e seus ingredientes - sal e salmoura. Diário Oficial da União, Poder Executivo, Brasília, DF, 27 Jul. 1999. Seção 1.

BRASIL. Ministério da pesca e aquicultura. Boletim Estatístico da Pesca e Aquicultura Brasil - 2011. Brasília. Disponível em: . Acesso em: 5 de janeiro de 2018.

BRASIL, Ministério da Agricultura, LANARA, Métodos analíticos oficiais para controle de produtos de origem animal e seus ingredientes: Métodos microbiológicos e físicoquímicos, Brasília,1993.

CICERO, L. H., FURLAN, E. F., TOMITA, R. Y., PRISCO, R. DE C. B., SAVOY, V. L. T., \& NEIVA, C. R. P. Estudo das metodologias de destilação na quantificação do Nitrogênio das Bases Voláteis Totais em pescada, tilápia e camarão. Brazilian Journal of Food Technology, 17(3), p. 192-197. 2014. https://doi.org/10.1590/1981-6723.5713

CODEX ALIMENTARIUS COMMISSION, Food and Agriculture Organization of the United Nations World Health Organization, Rome, p. 3-51, 1997.

COLLETO, D. Gerenciamento da segurança dos alimentos e da qualidade na indústria de alimentos. 2012. 46 f. Trabalho de Conclusão de Curso (Graduação) Curso de Engenharia de Alimentos. Universidade Federal do Rio Grande do Sul, Porto Alegre, 2012-

FAO, La Prevención de lasPérdidas de Pescado Curado, FAO, Doc. Téc. Pesca, (219):240p, 1985.

LIRA, G. M., \& PEREIRA, W. D. Avaliaçäo da qualidade de peixes comercializados na cidade de Maceió, AL. Higiene alimentar, p. 67-74. 2001. 
MORTIMORE, S. An exemple of some procedure used to assess HACCP systems within the food manufacturing industry, Food Control, v.11, 403-410p, 2000.

MOTARJEMI, Y. Regulatory Assessment of HACCP: a FAO/WHO Consultation on the of Government Agencies in Assessing HACCP, Switzerland, v.11, Food Control, 341343p, 2000.

OGAWA, M.; MAIA, E. L. Manual da Pesca, ed. Varela, Vol. 1, São Paulo.1999.

PEREIRA, A.S.; SHITSUKA, D.M.; PARREIRA, F.J.; SHITSUKA, R. Metodologia da pesquisa científica. [e-book]. 2018, Santa Maria. Ed. UAB/NTE/UFSM. Disponível em: https://repositorio.ufsm.br/bitstream/handle/1/15824/ Lic_Computacao_MetodologiaPesquisa-Cientifica.pdf?sequence=1. Acesso em: 03 Janeiro 2021.

ROPKINS, K., BECK, A. Evaluation of worldwide approaches to the use of HACCP to control food safety, $n^{\circ}$ 1, v.11, Trends in Food Sciense\& Technology, p.10-18,2000.

SANTOS, M.D. F. A pesca artesanal e a qualidade de pescados recem capturados em comunidades de São Francisco-BA.Universidade Federal da Bahia, p. 141.2013.

SEBRAE. Sistema de análise de riscos e controle dos pontos críticos na indústria da pesca, Manual de Auditoria, Rio de Janeiro, 2000, 20p.

SILVA, L. C. S, KOVALESKI, J. L, GAIA. S. Gestão da qualidade do produto no processo de produção industrial: um estudo de caso em uma indústria de bebidas. Revista de Engenharia e Tecnologia, Ponta Grossa, v.4, n.1, p.55-67, 2012.

SOUZA, A. L. M. D., Calixto, F. A. A., Mesquita, E. D. F. M. D., Packness, M. D. P., \& Azeredo, D. P. Histamine and traceability of fish: literaturereview. Arquivos do Instituto Biológico, 82, p.1-11, 2015.

STEVENSON, K.E. AND BERNARD. D.T. HACCP Establishing Hazard Analysis Critical Control Point Programs: A workshop manual. 2nd., Washington, D.C., Ed. The Food Processors Institute.1995.

VIEIRA, R. H. S. F. Microbiologia do Pescado In: Gonçalves, A. A tecnologia do Pescado: Ciência, Tecnologia, Inovação e Legislação. São Paulo: Atheneu, 2011, 33-42p.

Recebido em: 15/12/2021

Aprovado em: 18/01/2022

Publicado em: 23/01/2022 